Fauzan Al Safiq, Erlin Widya Fatmawati, 2018. Analisis Kepuasan Konsumen Sari Buah

Belimbing Manis (Arverrhoa carambola L.) (Studi Kasus Di UD Cemara Sari Kelurahan Karangsari Kecamatan Sukorejo Kota Blitar). Journal Viabel Pertanian. (2018), 12 (12) - 20-31

\title{
ANALISIS KEPUASAN KONSUMEN SARI BUAH BELIMBING MANIS (Arverrhoa carambola L) \\ (STUDI KASUS DI UD CEMARA SARI KELURAHAN KARANGSARI KECAMATAN SUKOREJO KOTA BLITAR)
}

\author{
Fauzan Al Safiq ${ }^{-1}$, Erlin Widya Fatmawati ${ }^{-2}$
}

1. Mahasiswa Program Studi Agribisnis Fakultas Pertanian, Universitas Islam Balitar, Blitar

2. Dosen Program Studi Agribisnia Fakultas Pertanian, Universitas Islam Balitar, Blitar

\begin{abstract}
ABSTRAK
This study aims to determine the attributes of starfruit juice "Cemara Sari" which is considered important by consumers as well as to find out the level of customer satisfaction and map of crabs from starfruit juice "Cemara Sari". Research has been carried out around star fruits agrotourism in Sukorejo Subdistrict, Karangsari Subdistrict, Blitar City, which began in February to March 2018. The research was conducted by distributing questionnaires and interviews with the respondents. The data obtained were tested using validity and reliability tests to determine the feasibility of the variables. used in the questionnaire, in addition to knowing the level of customer satisfaction using the Customer Satisfaction Index (CSI) and to find out the map quadrant attribute starfruit juice "Cemara Sari" using the Importance Peformance Analisys (IPA). The results showed that the variables in the questionnaire feasible to use with $r$ table of 0.196 and the results of the validity shows the lowest value is 0.448 and reliability (alpha) of 0.763. The results of the Customer Satisfaction Index (CSI) count show a value of 69.79\% and the Importance Peformance Analisys (IPA) address Quadrant 1 in the contents of the variable smell and price, Kudran 2 in the contents of the taste variable, shelf life, packaging ability to protect the product and practicality of packaging, 3 In the contents of the texture, product color and attractiveness of the variable, quadrant 4 is filled with the packaging color variable.
\end{abstract}

Keywords: juice, CSI and IPA

\section{Latar Belakang}

\section{PENDAHULUAN}

Sari buah merupakan suatu cairan yang tidak mengalami fermentasi yang di peroleh melalui proses pengepresan buah-buahan yang telah matang dan masih segar (Muchtadi,1997). Sedangkan sari buah blimbing adalah minuman ringan yang terbuat dari hasil perebusan buah belimbing yang di campur dengan air, gula, benzoat, Asam sitrat dan bahan pendukung lainya. Rasa dari sari buah belimbing mirip dengan buah blimbing yang 
Fauzan Al Safiq, Erlin Widya Fatmawati, 2018. Analisis Kepuasan Konsumen Sari Buah

Belimbing Manis (Arverrhoa carambola L.) (Studi Kasus Di UD Cemara Sari Kelurahan Karangsari Kecamatan Sukorejo Kota Blitar). Journal Viabel Pertanian. (2018), 12 (12) - 20-31

belum diolah rasanya manis dengan sedikit rasa asam selain itu juga memiliki warna kuning pekat.

Salah satu agroindustri yang mengolah hasil pertanian menjadi makanan dan minuman adalah UD Cemara Sari yang fokus mengolah buah belimbing, UD Cemara Sari ini masih tergolong dalam usaha jenis UMKM karena dalam memproduksi produknya masih menggunakan alat maual maupun semi modern, selain itu UD Cemara Sari sangat menonjolkan kearifan lokal dengan mengolah buah belimbing yang merupakan ciri khas dari desa karangsari.

Kurang terkenalnya produk sari buah belimbing, bahan baku tidak tersedia setiap tahun, serta harga yang di tetapkan lebih tinggi dari produk pesaing, selain itu distribusi produk yang kurang luas maka dari itu perlu adanya kajian mengenai kepuasan konsumen pada sari buah belimbing.

\section{Tujuan}

1. Untuk mengetahui atribut yang dianggap penting bagi konsumen sari buah belimbing yang di produksi oleh UD Cemara Sari.

2. Untuk mengetahui berapa besar tingkat kepuasan konsumen terhadap sari buah belimbing yang di produksi oleh UD Cemara Sari.

3. Untuk mengetahui peta kuadran atribut sari buah belimbing.

\section{METODE}

\section{Waktu dan Tempat}

Penentuan tempat penelitian ini di pilih dengan menggunakan teknik purposive sampeling (secara sengaja) di UD Cemara Sari yang beralamat di Jl. Kalpataru Desa Karangsari Kecamatan Sukorejo Kota Blitar. Penelitian ini akan dilaksanakan selama 2 bulan yaitu pada bulan Februari sampai Maret 2018.

\section{Metode Pengumpulan Data}

Data yang akan di ambil dalam penelitian ini berupa data primer dan data sekunder,data primer di dapat dari proses wawancara serta kuesioner yang di bagikan kepada responden sedangkan data sekunder di dapat dari sumber bacaan bisa berupa jurnal, skripsi, buku serta sumber-sumber bacaan lainya

\section{Metode Penentuan Sampel}

Penentuan sampel dilakukan dengan mengambil beberapa anggota dari populasi yang representative mewakili seluruh anggota populasi.Populasi dalam penelitian ini adalah seluruh konsumen sari buah belimbing merek "Cemara Sari". Responden ditentukan dengan teknik convenience sampling.Dalam analisis kepuasan konsumen ini peneliti mengambil 100 sampel dari keseluruhan populasi yang ada.

\section{Skala Pengukuran Variabel}


Fauzan Al Safiq, Erlin Widya Fatmawati, 2018. Analisis Kepuasan Konsumen Sari Buah

Belimbing Manis (Arverrhoa carambola L.) (Studi Kasus Di UD Cemara Sari Kelurahan Karangsari Kecamatan Sukorejo Kota Blitar). Journal Viabel Pertanian. (2018), 12 (12) - 20-31

Dalam penelitian ini pengukuran variabel menggunakan skala Likert yaitu digunakan untuk mengukur sikap, pendapat dan persepsi seseorang ataupun sekelompok orang tentang fenomena sosial (Sugiyono, 2008). Variabel yang di ukur dalam penelitian ini meliputi kualitas produk, kemasan produk, dan harga produk menggunakan skala likert.Sebagai tolak ukur bagi konsumen agar dapat menilai tingkat kepuasan, menggunakan skala likert dengan nilai 1-5.

\section{Uji Validitas}

Untuk menguji tingkat validitas hasil kuesioner dalam penelitian ini menggunanakan metode uji korelasi Bivariate Pearson dengan uji signifikansi koefisien korelasi pada taraf signifikansi 5\%. Validitas bisa di ukur dengan membandingakan $\mathrm{r}$ hitung dengan $r$ tabel dengan ketentuan degree of freedom $(\mathrm{df})=\mathrm{n}-2$.

\section{Uji Reliabilitas}

Dalam penelitian ini untuk menguji reliabilitasnya menggunakan metode Cronbach's Alpha. Menurut (Nazir, 2003) Tingkat reliabilitas dapat diukur dengan membandingkan nilai Cronbach's Alpha (a) sebagai berikut:

JIka Cronbach's Alpha $(a)>0,60$ maka reiable.

Jika Cronbach's Alpha $(a)<0,60$ maka tidak reiable.

\section{Customer Satisfaction Indeks (CSI)}

Dalam penelitian ini menggunakan Customer satisfaction indeks model 1, cara menghitung CSI adalah nilai rata-rata pada kepentingan (I) dijumlahkan sehingga diperoleh Y dan juga hasil kali I dengan P pada skor (S) di jumlahkan dan diperoleh $\mathrm{T}$ (Maiyanti dkk, 2010). CSI dapat di hitung menggunakan rumus

$$
\mathrm{CSI}=\frac{\mathrm{T}}{5 \mathrm{Y}} \mathrm{X} 100 \%
$$

Kepuasan konsumen dapat dilihat dari kriteia tingkat kepuasan konsumen dengan kriteria sebagai berikut (Irawan, 2002)

\begin{tabular}{cc}
\hline Nilai CSI & Kriteria CSI \\
\hline $0,81-1,0$ & Sangat Puas \\
$0,66-0,80$ & CukupPuas \\
$0,51-0,65$ & Netral \\
$0,35-0,50$ & Tidak Puas \\
$0,00-0,34$ & Sangat Tidak Puas \\
\hline
\end{tabular}

Sumber: (Jurnal Teknologi Dan Industri Pertanian Indonesia - Vol. , No.02,2016)

\section{Importance Peformance Analisys (IPA)}


Fauzan Al Safiq, Erlin Widya Fatmawati, 2018. Analisis Kepuasan Konsumen Sari Buah

Belimbing Manis (Arverrhoa carambola L.) (Studi Kasus Di UD Cemara Sari Kelurahan Karangsari Kecamatan Sukorejo Kota Blitar). Journal Viabel Pertanian. (2018), 12 (12) - 20-31

Importance Peformance Analisys digunakan dalam mencari hubungan antara tingkat kepentingan dan tingkat kepuasan (performance). Untuk menganalisis perceived quality, di lakukan dengan cara membandingkan performance (kinerja suatu produk) dengan importance ( tingkat kepentingan produk). Perbandingan performance dan importance dirangkum dalam suatu diagram cartecius, yang di bagi dalam empat kuadran. Penilaian tingkat kinerja yang dapat mempengaruhi kepuasan konsumen akan diwakili huruf $\mathrm{x}$, sedangkan untuk penilaian tingkat kepentingan diwakili oleh huruf $\mathrm{y}$.

Berikut adalah pembagian kudran dalam diagram kartesius berdasarkam keadaan item-item yang diteliti menurut (Rangkuti, 2003):

Kuadran 1 (Prioritas Utama)

Kuadranini berisi item-item dengan tingkat kepentingan yang relatif tinggiakan tetapi realitanya belum sesuai dengan harapan konsumen.

Kuadran 2 (Pertahankan Prestasi)

Kuadranini berisi item-item dengan tingkat kepentingan relatif tinggi dan tingkat kepuasan konsumenterhadap item disini relatif tinggi.

Kuadran 3 (Prioritas Rendah)

Kuadran ini berisi item-item dengan tingkat kepentingan relatif rendah dan kenyataanya memiliki kinerja yang tidak terlalu istimewa dengan tingkat kepuasan yang juga relatif rendah.

Kuadran 4 (Berlebihan)

kuadran ini berisi item-item dengan tingkat kepentingan yang relatif rendah dan konsumen merasakan terlalu berlebihan dengan tingkat kepuasan yang relatif tinggi.

\section{HASIL DAN PEMBAHASAN}

HASIL

\section{Uji Validitas}

\begin{tabular}{llcc}
\hline No. Atribut & r hitung & $\begin{array}{c}\text { Rtabel } \mathrm{n}=100-2 \\
\mathrm{a}=5 \%\end{array}$ \\
\hline 1 & Warna Sari Buah & 0,524 & 0,196 \\
2 & Aroma & 0,643 & 0,196 \\
3 & Tekstur & 0,647 & 0,196 \\
4 & Rasa & 0,570 & 0,196 \\
5 & Masa Simpan & 0,535 & 0,196 \\
6 & Daya Tarik Ilustrasi & 0,565 & 0,196 \\
7 & Warna Kemasan & 0,538 & 0,196 \\
8 & Kemampuan Kemasan Melindungi Produk & 0,645 & 0,196
\end{tabular}


Fauzan Al Safiq, Erlin Widya Fatmawati, 2018. Analisis Kepuasan Konsumen Sari Buah

Belimbing Manis (Arverrhoa carambola L.) (Studi Kasus Di UD Cemara Sari Kelurahan Karangsari Kecamatan Sukorejo Kota Blitar). Journal Viabel Pertanian. (2018), 12 (12) - 20-31

$\begin{array}{clcc}9 & \text { Kepraktisan Kemasan } & 0,579 & 0,196 \\ 10 & \text { Harga } & 0,448 & 0,196\end{array}$

Dari data di atas dapat dilihat bahwa nilai dari setiap variabel sebagai berikut warna produk $(0,524)$, aroma produk $(0,643)$ tekstur produk $(0,570)$, rasa produk $(0,570)$, masa simpan produk $(0,535)$, daya tarik ilustrasi $(0,565)$, warna kemasan $(0,538)$, kemampuan kemasan melindungi produk $(0,645)$, kepraktisan kemasan $(0,579)$, harga produk $(0,448)$.

\section{Uji Reliabilitas}

Tabel. Hasil Nilai Alpha

\begin{tabular}{ccc}
\hline No & Alpha & r tabel \\
\hline 1 & 0,763 & 0,196 \\
\hline
\end{tabular}

Tabel. Hasil Uji Reliabilitas Setiap Item

\begin{tabular}{clc}
\hline No. & \multicolumn{1}{c}{ Atribut } & Cronbach's Alpha \\
\hline 1 & Warna Sari Buah & 0,758 \\
2 & Aroma & 0,736 \\
3 & Tekstur & 0,730 \\
4 & Rasa & 0,741 \\
5 & Masa Simpan & 0,748 \\
6 & Daya Tarik Ilustrasi & 0,743 \\
7 & Warna Kemasan & 0,748 \\
8 & Kemampuan Kemasan Melindungi Produk & 0,730 \\
9 & Kepraktisan Kemasan & 0,740 \\
10 & Harga & 0,761 \\
\hline
\end{tabular}

Dari data di atas di dapat nilai total alpha sebesar 0,763 dan $\mathrm{r}$ tabel berjumlah 0,196 lalu setiap item memiliki nilai cronbach's alpha sebagai berikut warna produk $(0,758)$, aroma produk $(0,736)$, tekstur produk $(0,730)$, rasa produk $(0,741)$, masa simpan produk $(0,748)$, daya tarik ilustrasi $(0,743)$, warna kemasan $(0,748)$, kemampuan kemasan melindungi produk $(0,730)$, kepraktisan kemasan $(0,740)$, dan harga produk $(0,761)$.

\section{Kepuasan Konsumen}

Tabel 4.9 Customer Satisfaction Indeks (CSI)

\begin{tabular}{|c|c|c|c|c|}
\hline \multicolumn{5}{|c|}{ Nilai rata-rata } \\
\hline No & Atribut & $\begin{array}{c}\text { Tingkat } \\
\text { Kepentingan (I) }\end{array}$ & $\begin{array}{c}\text { Tingkat } \\
\text { Kinerja }(\mathrm{P})\end{array}$ & $\begin{array}{c}\text { Skor (S) } \\
\text { (IxP) }\end{array}$ \\
\hline 1 & Warna & 3.65 & 3.35 & 12.2275 \\
\hline 2 & Aroma & 3.78 & 3.3 & 12.474 \\
\hline 3 & Tekstur & 3.68 & 3.44 & 12.6592 \\
\hline 4 & Rasa & 4.27 & 3.58 & 15.2866 \\
\hline
\end{tabular}


Jurnal Viabel Pertanian Vol. 12 No.2 November 2018

p-ISSN: 1978-5259 e-ISSN: 2527-3345

Copyright@UNISBA Blitar, http://viabel.unisbablitar.ejournal.web.id

Fauzan Al Safiq, Erlin Widya Fatmawati, 2018. Analisis Kepuasan Konsumen Sari Buah

Belimbing Manis (Arverrhoa carambola L.) (Studi Kasus Di UD Cemara Sari Kelurahan Karangsari Kecamatan Sukorejo Kota Blitar). Journal Viabel Pertanian. (2018), 12 (12) - 20-31

\begin{tabular}{clccc}
\hline 5 & Masa Simpan & 4.01 & 3.69 & 14.7969 \\
6 & Daya Tarik Ilustrasi & 3.22 & 3.4 & 10.948 \\
7 & Warna Kemasan & 3.35 & 3.51 & 11.7585 \\
8 & Kemampuan Kemasan & 3.85 & 3.63 & 13.9755 \\
& Melindungi Produk & & & \\
9 & Kepraktisan Kemasan & 3.83 & 3.68 & 14.0944 \\
10 & Harga & 3.94 & 3.28 & 12.9232 \\
\hline & Total rata-rata & $\mathbf{3 7 . 5 8}$ & $\mathbf{1 3 1 . 1 4 3 8}$ \\
\hline
\end{tabular}

$$
\begin{aligned}
\text { CSI } & =\frac{T}{\boldsymbol{E v}_{\mathbf{v}}} \times 100 \% \\
& =\frac{131.1438}{} \times 100 \% \\
& =69.79 \%
\end{aligned}
$$


Fauzan Al Safiq, Erlin Widya Fatmawati, 2018. Analisis Kepuasan Konsumen Sari Buah

Belimbing Manis (Arverrhoa carambola L.) (Studi Kasus Di UD Cemara Sari Kelurahan Karangsari Kecamatan Sukorejo Kota Blitar). Journal Viabel Pertanian. (2018), 12 (12) - 20-31

\section{Peta Kuadran}

Gambar. Hasil Importance Performance Analisys

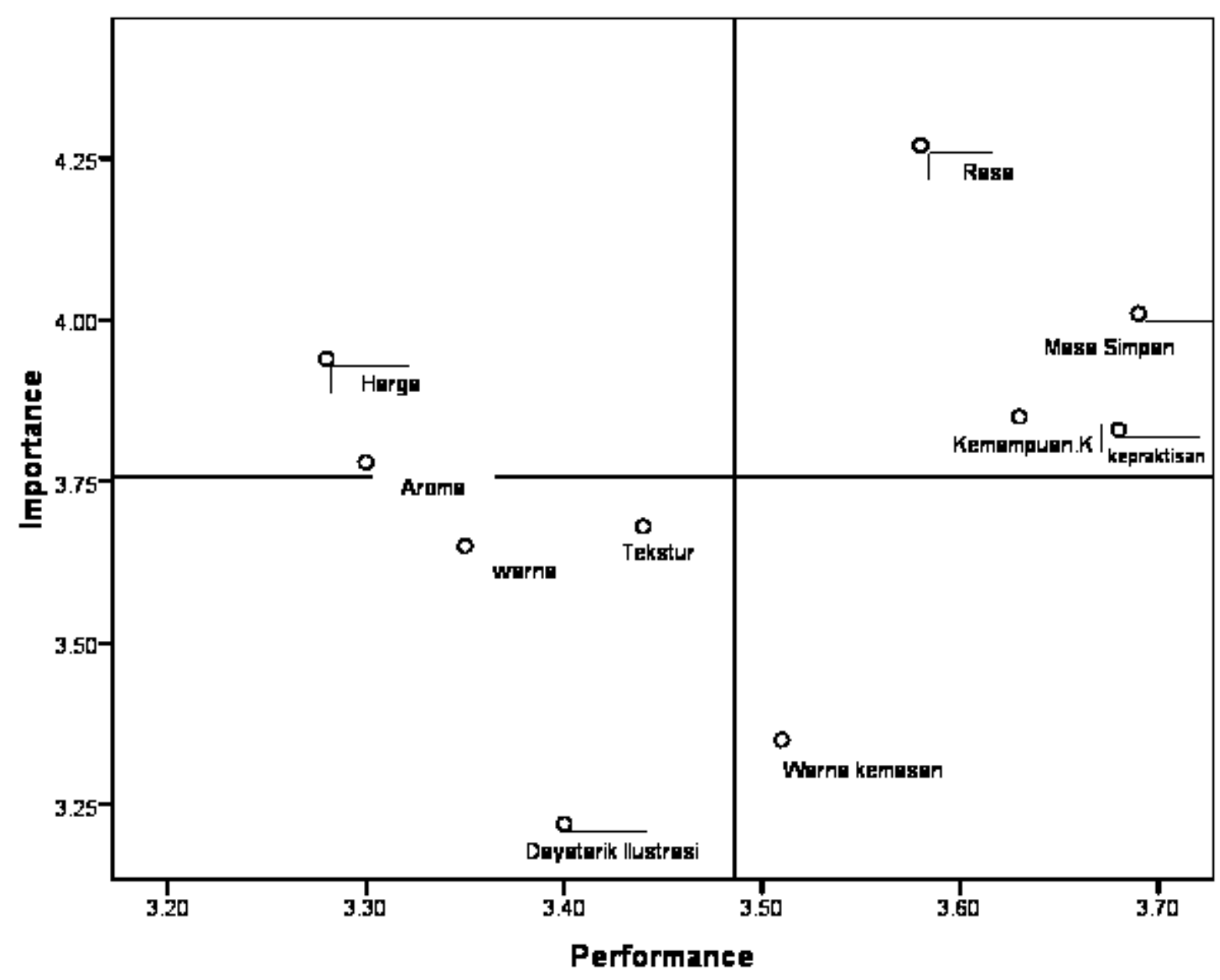

Dari hasil SPSS di atas Importance Peformance Analisys dapat di golongkan sebagai berikut:

1. Kuadran 1 (Harga, dan Aroma)

2. Kuadran 2 (Rasa, Masa Simpan, Kemampuan Kemasan Melindungi Produk, dan Kepraktisan Kemasan)

3. Kuadran 3 (Tekstur, Warna, dan Daya Tarik Ilustrasi)

4. Kuadran 4 (Warna Kemasan) 
Fauzan Al Safiq, Erlin Widya Fatmawati, 2018. Analisis Kepuasan Konsumen Sari Buah

Belimbing Manis (Arverrhoa carambola L.) (Studi Kasus Di UD Cemara Sari Kelurahan Karangsari Kecamatan Sukorejo Kota Blitar). Journal Viabel Pertanian. (2018), 12 (12) - 20-31

\section{PEMBAHASAN}

\section{Uji Validitas}

Tingkat validitas dalam penelitian ini di hitung dengan teknik membandingkan hasil $r$ hitung dengan nilai $r$ tabel menggunakan ketentuan degree of freedom $(\mathrm{df})=\mathrm{n}-2$, dengan uji signifikansi koefisien korelasi pada taraf signifikansi 5\%. Hasil perhitungan menghasilkan $\mathrm{df}=100-2$ Maka di dapat $\mathrm{r}$ tabel sebesar 0,196.

Dari perbandingan antara data dan rumus di atas dapat di simpulkan bahwa seluruh atribut dalam penelitian ini dinyatakan valid dengan nilai tertinggi adalah tekstur produk dengan $r$ hitung 0,647 serta yang terendah adalah harga dengan $r$ hitung 0,448.

\section{Uji Reliabilitas}

Dari analisis data di dapat nilai Alpha sebesar 0,763 sedangkan nilai r kritis (uji 2 sisi) pada signifikansi 5\% dengan $\mathrm{n}=100-2$, di dapat sebesar 0,196. Maka dapat di simpulkan bahwa butir-butir instrumen penelitian tersebut reliabel. Selain itu dari perhitungan semua atribut memiliki hasil Cronbach's Alpha lebih besar dari 0,60 dapat di simpulkan bahwa seluruh atribut yang di gunakan sudah reliabel hasil perhitunganCronbach's Alpha terbesar adalah harga dengan nilai Cronbach's Alpha sebesar 0,761 serta yang terendah merupakan tekstur produk dan kemampuan kemasan melindungi produk denganhasil perhitunganCronbach's Alpha sebesar 0,730.

\section{Kepuasan Konsumen}

Perhitungan Customer Satisfaction Indeksmenunjukkan hasil sebesar 69,79\% hal ini menunjukkan bahwa secara keseluruhan atribut saribuah belimbing ini sudah masuk dalam kategori puas hal ini di dapat setelah membandingkan hasil hitung CSI dengan pembagian kriteria oleh Irawan bahwa jika nilai CSI pada 0,66-0,80 adalah puas.

\section{Peta Kuadran}

\section{Kuadran 1}

kuadranini berisi item-item dengan tingkat kepentingan yang relatif tinggi akan tetapi realitanya belum sesuai dengan harapan konsumen.

Item-item yang berada dalam kuadran ini harus ditingkatkan kinerjanya item yang berada dalam kuadran ini sebagai berikut,harga sari buah serta aroma saribuah harga sari buah bagi para responden masih terlalu mahal di bandingkan dengan produk sejenis lainya dan aroma dari saribuah belimbing di anggap kurang nikmat. Harga serta aroma sari buah adalah faktor pendorong kepuasan konsumen maka dari itu perlu adanya perbaikan pada atribut ini agar sesuai dengan keinginan konsumen dan tercapailah kepuasan konsumen.

\section{Kuadran 2}

Kuadranini berisi item-item dengan tingkat kepentingan relatif tinggi dan tingkat kepuasan konsumenterhadap item disini relatif tinggi.Item yang masuk kuadran ini dapat dipertahankan karena setiap item dalam kuadran ini menjadikan produk lebiht unggul dari produk pesaing dimata konsumen.Item yang beradadi dalam kuadran ini yaitu, rasa, masa simpan produk, kemampuan kemasan melindungi produk dan kepraktisan kemasan.Berarti 
Fauzan Al Safiq, Erlin Widya Fatmawati, 2018. Analisis Kepuasan Konsumen Sari Buah Belimbing Manis (Arverrhoa carambola L.) (Studi Kasus Di UD Cemara Sari Kelurahan Karangsari Kecamatan Sukorejo Kota Blitar). Journal Viabel Pertanian. (2018), 12 (12) - 20-31

UD Cemara Sari sebagai produsen sari buah belimbing sudah baik dalam menjalankan atribut-atribut ini dan harus mempertahankan keadaan ini agar konsumen terus merasa puas dengan produk yang dibuat.

\section{Kuadran 3}

Kuadranini berisi item-item dengan tingkat kepentingan sedikit rendah dan kenyataanya memiliki kinerja yang tidak terlalu istimewa dengan tingkat kepuasan yang juga sedikit rendah. Item yang berada di dalam kuadran ini memberikan manfaat yang begitu kecil bagi konsumen.Item yang berada di dalam kuadran ini ada tida yaitu, tekstur, warna sari buah dan daya tarik ilustrasi dalam hal ini UD Cemara Sari selaku produsen sari buah belimbing perlu memperhatikan kinerja atribut-atribut ini agar tidak berubah menjadi sangat penting karena konsumen dapat berubah dari yang awalnya menganggap suatu atribut tidak penting menjali sangat penting.

\section{Kuadran 4}

kuadranini berisi item-item dengan tingkat kepentingan yang relatif rendah dan konsumen merasakan terlalu berlebihan dengan tingkat kepuasan yang relatif tinggi.

Item yang berada di dalam kuadran ini adalah warna kemasan jadi warna kemasan bisa di ubah menjadi sedikit pudar agar biaya produksi lebih kecil sehingga produsen memiliki keuntungan lebih.

\section{KESIMPULAN DAN SARAN}

\section{KESIMPULAN}

Berdasarkan uji validitas dan reliabilitas item-item yang dapat dipertimbangkan oleh responden adalah warna produk, aroma produk, tekstur produk, rasa produk, masa simpan produk, daya tarik ilustrasi kemasan, warna kemasan, kemampuan kemasan melindungi produk, kepraktisan kemasan dan harga produk.

Penghitungan dari Customer Satisfaction Indeks (CSI) menunjukkan nilai sebesar 0,69 hal ini menunjukkan bahwa produk sari buah belimbing "Cemara Sari" sudah mampu memuaskan konsumenya.

Dari hasil perhitungan Importance Peformance Analisys (IPA) di dapat hasil bahwa item yang masuk dalam kuadran satu adalah aroma dan harga dimana item-item ini harus segera diperbaiki kualitasnya agar mampu menambah kepuasan dari konsumen, item yang masuk pada kuadran dua adalah rasa, masa simpan, kemampuan kemasan melindungi produk, dan kepraktisan kemasan item-item yang masuk dalam kuadran ini harus bisa dipertahankan agar kepuasan konsumen tetap terjaga, item yang berada di kuadran tiga adalah tekstur, warna, dan daya tarik ilustrasi jadi item-item yang masuk dalam kuadran ini sebaiknya dijaga karena konsumen memiliki sifat yang mudah berubah yang dulunya menganggap suatu atribut itu tidak penting bisa berubah menjadi penting, item yang berada di kuadran empat adalah warna kemasan dimana konsumen menganggap bahwa warna kemasan sangat memuaskan padahal dianggap tidak penting maka dari itu perlu adanya penurunan agar menambah efisiensi produksi.

\section{SARAN}

1. Produsen sebaiknya mempertahankan kinerja dari item-item yang sudah di anggap memuaskan oleh konsumen sari buah beliming "Cemara Sari". 
Fauzan Al Safiq, Erlin Widya Fatmawati, 2018. Analisis Kepuasan Konsumen Sari Buah

Belimbing Manis (Arverrhoa carambola L.) (Studi Kasus Di UD Cemara Sari Kelurahan Karangsari Kecamatan Sukorejo Kota Blitar). Journal Viabel Pertanian. (2018), 12 (12) - 20-31

2. Item-item yang belum mampu memuaskan konsumen sebaiknya ditingkatkan lagi kinerjanya agar mampu meningkatkan kepuasan konsumen sari buah belimbing "Cemara Sari".

\section{DAFTAR PUSTAKA}

Adit Nobaka., 2010 "Pengertian Konsumen”. (Online).2 Februari 2018. https://aditnobaka.wordpress.com/2010/10/08/pengertian-konsumen/.

Admin., 2014 “pengertian kemasan menurut para ahli”.(Online).27 Maret 2018. http://globallavebookx.blogspot.co.id/2014/12/pengertian-kemasan-menurut-paraahli.html

Admind., 2018 "Kandungan Nutrisi dan Manfaat Buah Belimbing”. (Online). 23 Februari 2018.https://www.google.com/search?hl=in\&source=android-launcherwidget $\& q=$ nutrisi+buah+belimbing \&gws_rd=ssl.

Ahidin Udin. 2015 Membangun Kepuasan Pelanggan Melalui Kualitas Produk Tape Ketan Daun Jambu Di Kecamatan Cibeureum Kabupaten Kuningan Provinsi Jawa Barat. Jurnal Ilmiah Prodi Manajemen Universitas Pamulang Vol.3 No.1.

Amalia F., 2014 "BAB II Tinjauan Pustaka 2.1 Pengertian Konsumen Menurut Dewi”.(Online).18 Februari 2018 eprints.polsri.ac.id.

Andre Ong. 2014 Nalisis Customer Satisfaction Index(CSI) Produk Dan Kepuasan Pelanggan Terhadap Kualitas Produk UMKM Rumput Laut Situbondo.Media MahardhikaVol. 12 No. 3 Mei 2014

Badan Pusat Stastitik (BPS) 2015 “jumlah perusahaan menurut 2-digit KBLI (unit)"

Baswarsiati, Purnomo Sudarmadi, Sudaryono Tri. 2013 Manisnya Belimbing Karangsari Blitar. Balai Pengkajian Teknologi Pertanian (BPTP) Jawa Timur.

Dian Lulu, Deoranto Panji, Morita dhita. 2017 Analisis Persepsi Konsumen Menggunakan Metode Importance Performance Analysis Dan Customer Satisfaction Index.Jurnal Industri Vol 4 No 2 Hal 74 - 81 Customer Satisfaction Index.

Eka Heru, Santoso Imam, Anggraini Sakunda. 2013Analisis Pengaruh kualitas Pelayanan Terhadap Kepuasan Konsumen Menggunakan Metode IPA(Importance Performance Analysis) Dan CSI(Customer Satisfaction Index) Studi Kasus Pada Toko Oen, Malang. 
Fauzan Al Safiq, Erlin Widya Fatmawati, 2018. Analisis Kepuasan Konsumen Sari Buah

Belimbing Manis (Arverrhoa carambola L.) (Studi Kasus Di UD Cemara Sari Kelurahan Karangsari Kecamatan Sukorejo Kota Blitar). Journal Viabel Pertanian. (2018), 12 (12) - 20-31

Hertanto Eko, 2014 “Customer Satisfaction Indeks”. (Online). 12 Februari 2018 http://www.academia.edu/30414247/CUSTOMER_SATISFACTION_I DEX_CSI_MODEL_1_MANAJEMEN_PEMASARAN.

Imran Supriyo, Murtisari Amelia, dan Murni Ni Ketut. 2014 Analisis Nilai Tambah Keripik Ubi Kayu di UKM Barokah Kabupaten Bone Bolango.

Jurnal Perspektif Pembiayaan dan Pembangunan Daerah.Vol.1 No. 4.

Indra Sri,Irmeilyana,Verawaty. 2016 Aplied Customer Satisfaction Index (CSI) and Importance- Performance Analysis (IPA) to know Student Satisfaction Level of Sriwijaya University Library Services. Jurnal Jurusan Matematika FMIPA Unsri

Kurnia Eka, Silvia Evanila, Efendi Zulman. 2016 Analisis Kue Baytat Bengkulu. Jurnal Teknologi Dan Industri Pertanian Indonesia.Vol.8 No.2.

Muchtadi., 1997 “ANALISIS PANGAN”.(Online). 16 Desember 2017. www.analisispangan.com/2016/10sari-buah-dan-tahapan-prosespembuatan.html?m=1.

Sinun Ahmad. 2017 Analisis Kepuasan Pengguna LMS Berbasis Web Dengan Metode Servqual, IPA Dan CSI. Jurnal Invormatika Vol.4 No.1.

Srijayanti Chichi. 2015 Tingkat Kepuasan Konsumen "Sop Buah Ica” Di Boulevard Manado.Jurnal Universitas Sam Ratulangi Manado.

Sucipto Sucipto, Eka Yunita, Asmaul Siti. 2015 Analisis Keterkaitan Atribut Kemasan Teh Siap Saji Dan Etnik Terhadap Kepuasan Konsumen. Jurnal Teknik Industri ISSN: 1411-6340 233.

Sulistyo Joko. (2010) 6 Hari Jago SPSS 17: Cakrawala, Yogyakarta.

Sunyoto Danang. (2011) Metodologi Penelitian Untuk Ekonomi: CAPS, Yogyakarta.

Sunyoto Danang. (2015) Perilaku Konsumen dan Pemasaran: CAPS, Yogyakarta.

Susila Budi, Sumarwan Ujang, Kirbrandoko. 2014 Analisis Kepuasan Konsumen Terhadap Brand Switching Behavior Minuman Teh Dalam Kemasan. Jur. Ilm. Kel. \& KonsVol. 7, No. 3.

Tihbia Yannya, (2013) Analisis Kepuasan Konsumen Terhadap Minuman Sari Buah Jeruk COUNTRY CHOICE Di Kota Bogor, IPB: Bogor. 
Fauzan Al Safiq, Erlin Widya Fatmawati, 2018. Analisis Kepuasan Konsumen Sari Buah

Belimbing Manis (Arverrhoa carambola L.) (Studi Kasus Di UD Cemara Sari Kelurahan Karangsari Kecamatan Sukorejo Kota Blitar). Journal Viabel Pertanian. (2018), 12 (12) - 20-31

Tunjungsari Maulina, Haryono Dwi, Aring Dyah. 2015 Kepuasan Dan Loyalitas Konsumen Ibu Rumah Tangga Dalam Mengkonsumsi Santan Sun Kara Di Kota Bandar Lampung.JIIA.Vol.3 No.3.

Udayana, (2011) Peran Agroindustri Dalam Pembangunan Pertanian Edisi 44: Singhadwala.

Usman Arfan. 2013 Analisis Kepuasan Pengguna Jasa Terhadap Penerapan Manajemen Rekayasa Konstruksi Profesional Rukodi Kawasan Bussiness Park Kota Gorontalo. Jurnal Ilmiah MEDIA ENGINEERING Vol. 3, No.

WM Chery. 2017 Analisis Tingkat Kepuasan Konsumen Terhadap Sembilan Kebutuhan Bahan Pokok (SEMBAKO) Pada Pasar Tradisional Dan Pasar Moderen di Kota Pekanbaru.

Yosan Bagus. R. 2017 Analisis Kualitas Produk dan Korelasinya Terhadap Tingkat Kepuasan Konsumen Dengan Metoda Statistical Process Control. Sinergi Vol.21 No.3.

Yulia Roza Prima, M.baga Lukman, Djohar Septiadi. 2016 Kepuasan Konsumen Terhadap Pelayanan Apotek Dan Tingkat Pengetahuan Konsumen Mengenai Standar Pelayanan Kefarmasian Yang Berlaku (Studi Kasus Di Kota Depok).Jurnal Aplikasi Bisnis dan Manajemen Vol.2 No.3. 